\title{
A parasitological survey for bovine trypanosomosis in the livestock/wildlife ecozone of Northern Tanzania
}

\author{
Emanuel S. Swai, Jackson E. Kaaya \\ Veterinary Investigation Center \\ Box No. 1068, Arusha, Tanzania \\ Corresponding author: Emanuel S. Swai, Email: ESswai@gmail.com, Cell: +255-754-816967 \\ Received: 28-12-2011, Accepted: 27-01-2012, Published Online: 12-05-2012 \\ doi: $10.5455 /$ vetworld.2012.459-464
}

\begin{abstract}
Aim: Tsetse-transmitted animal and human trypanosomosis is considered to be one of the major constraints to improved livestock and agricultural production in sub-Saharan Africa. A cross sectional survey to determine the prevalence of trypanosomosis and identifying trypanosome species infecting cattle was conducted in Makuyuni division, Arusha region of northern Tanzania, an area where livestock and wildlife graze together.

Materials and methods: A total of 239 indigenous Tanzania short horn zebu cattle at four different villages, and of different ages and sex, were randomly selected and sampled. Field examination of Giemsa stained thick and thin blood smears was undertaken.

Results: The overall prevalence of slides positive for bovine trypanosomosis was $5 \%$ (95\% [confidence interval], CI $=2.6$ 8.6). The prevalence was significantly higher in Mswaki juu village (7\%) and lower in Ortukai (3\%). Of the positive cattle, $8 / 12(66.6 \%)$ had infections with T. vivax and 4/12 (33.3\%) T. congolense. No cases of T. brucei were detected. Animals with poor $(13.7 \%)$ body score were significantly associated with high prevalence of trypanosomes infection than animals with $\operatorname{good}(2.7 \%)$ score. Prevalence of trypanosomes infections was significantly higher in males $(8.42 \%)$ than in females $(2.47 \%)$ and increased markedly in cattle aged $>4.5$ years, with no significant difference among the age group.

Conclusion: Because of the risk of trypanosomosis in the Mswaki juu, a locality which is close to a wildlife Reserve; integrated tsetse and trypanosomosis control strategies need to be improved and enforced.

Keywords: cattle; prevalence; livestock/wildlife ecosystem; trypanosomes; Tanzania
\end{abstract}

To cite this article :

Swai ES, Kaaya JE (2012) A parasitological survey for bovine trypanosomosis in the livestock/ wildlife ecozone of Northern Tanzania, Vet World 5(8): 459-464. doi: 10.5455/vetworld.2012.459-464

\section{Introduction}

Tsetse-transmitted animal and human trypanosomosis is considered to be one of the major constraints to improved livestock and agricultural production in sub-Saharan Africa (SSA) [1]. While tsetse-borne trypanosomosis is excluding some $13,127,000$ ha of agriculturally suitable land for livestock and wildlife grazing in Tanzania; 11 million head of cattle, 7 million small ruminants, nearly 4 million people and 2 million wildlife animal species are at the risk of contracting trypanosomosis at any one time [2], though these figures many vary over years.

The most important tsetse-borne diseases in Tanzania include bovine and human trypanosomosis caused by the four major species of salvarian trypanosomes namely, T. congolense, $T$. vivax and $T$. brucei brucei and T. brucei rhodesiense. One of the major factors influencing the transmission of animal and human trypanosomosis is the vector-tsetse fly distributions [3]. The main field vectors for transmission of trypanosomosis includes the seven species of Glossina, namely $G$. morsitans, $G$. pallidipes, G. longipennis, G. brevipalpis, G. austeni, G. swynertonni and G. fuscipes [3]. Past records of the prevalence of the disease in Tanzania concentrated mostly in tsetse endemic areas and there is a paucity of information for areas that were considered to have lower densities of flies as in the Maasai plains/steppes or wildlife livestock ecosystem or interface areas [4,5]. Evidence of human specific trypanosomes species, namely $T$. brucei rhodesiense, have been demonstrated in livestock/ wildlife ecosystem areas [5-7]. For example, tsetse surveys carried out on the areas adjacent to the Tarangire National Park revealed apparently high tsetse densities of G. swynnertoni and $G$. pallidipes, the main vectors for $T$. brucei 
rhodesiense [8]. However reports on the situation of wildlife and domestic animal trypanosomosis are largely unknown. Given the situation of animal trypanosomosis and the importance of domestic and wild animals as reservoirs for T. brucei rhodesiense $[6,9]$, a survey was carried out on villages adjacent to Tarangire National park so as to form a basis for justifying the planned implementation of the integrated tsetse and trypanosomosis control measures on the area [10].

The objective of this parasitologal survey was therefore, (i) to estimate the prevalence of bovine trypanosomosis, (ii) identify the trypanosome species involved, and (iii) assess the relationship between trypanosomes prevalence and some risk factors responsible for maintenance and transmitting the disease in the study area.

\section{Materials and Methods}

Study area: The study was conducted in four villages belonging to Makuyuni division, Monduli district, Arusha region. The division is located $80 \mathrm{~km}$ South West of Arusha town. The criterion for selection of the Makuyuni division was the high densities of cattle and the close proximity to the 2 major wildlife parks, namely Tarangire to the south and Lake Manyara to the north. Geographically, Makuyuni division lies at latitude $03^{\circ} 34^{\prime} 04^{\prime \prime}$ South and $036^{\circ} 05^{\prime} 01^{\prime \prime}$ East. The area is semi-arid with annual average rainfall of 600-700 $\mathrm{mm}$ and an elevation of $1200 \mathrm{~m}$ above sea level. The vegetation is mainly Acacia cammiphora bushland, wooded savanna with short grass. The rains are normally concentrated in two seasons: from the end of March to May, and the end of October to December. Mean temperature ranges from 15 to $30{ }^{\circ} \mathrm{C}$. Administratively, Makuyuni division is composed of 2 wards and 8 villages. The study was carried out from October to November 2006.

Cattle husbandry system: The study animals were indigenous breeds of cattle, Tanzania short horn zebu (TSHZ) reared under extensive husbandry which allows free grazing, usually mixed with livestock from other villages and wildlife. The animals are housed at night in bomas or kraals constructed from thorny tree branches to protect them from thieves and predators. The breeding system used is natural mating, with bulls running freely with females all year round. No supplementary feeding is given.

Study animal selection and sampling strategy: To increase the geographical extent of the study, the two wards of Makuyuni division were included in the study. The smallest administrative units (villages) and farms were selected by stratified random sampling method. First, all villages were classified according to wards. Two villages from each of the two wards were then selected using random numbers to give a total of 4 villages. All villages were eligible for selection. In the second stage, through collaboration with division livestock field officer, a list of all household owning cattle (subsequently referred to as farms) was compiled and ten from each village selected, using random numbers, to give a total of 40 farms.

The prevalence of trypanosomes infections has not known a priori then $30 \%$ prevalence and $5 \%$ tolerable error were assumed when determining the desired size of cattle to be sampled. The sample size (239) was determined according to the method described by Thrusfield [11]. The age of the selected animals was determined by dentition and categorized as follows: immature, 1.5-2.5 years old; mature, $>2.5$ 4.5 years old; and older $>4.5$ years old. Selected animals were restrained in a kraal or boma using sisal ropes and nose rings. Thin blood was drawn from ear vein using a sharp hypodermic needle. A drop of blood was taken near one end of the clean glass slide and another slide used to prepare the blood smear. Prepared blood smears were air-dried, labelled along with collection of animal bio-data, i.e. sex, body condition score (BCS) at a time of visit, categorized as 'poor' or 'good'.

Parasitological examination: The dried blood smears were fixed in absolute methyl alcohol for $5 \mathrm{~min}$ and allowed to dry. The dry smears were placed in a glass staining jar containing working 10\% Giemsa stain solution for $20 \mathrm{~min}$. Subsequently the smears were taken out and washed with phosphate buffer solution (PBS) to remove excess stain. The slides were allowed to dry in air and then examined by microscope under oil immersion with a magnification of $100 \mathrm{x}$ objective lens [12]. Ten microscopic fields in each smear were examined in order to establish whether the smear was positive or negative. Species identification was confirmed by morphological examination of trypanosomes on Giemsa stained thin blood smear as described by Murray et al., [13].

Ethical consideration: During the survey visits, the interviewers introduced themselves and explained the objectives and methodology of the study to all cattle owners or their representative. Verbal consent was then sought from all the interviewees before proceeding. Approval and clearance for the study was obtained from the District Veterinary office. 
Table-1. Prevalence of trypanosome infections and species of trypanosomes identified in cattle

\begin{tabular}{|c|c|c|c|c|c|c|c|c|}
\hline \multirow[t]{2}{*}{ Village } & \multirow[t]{2}{*}{ No. examined } & \multirow[t]{2}{*}{ No. Posistive } & \multirow[t]{2}{*}{ Prevalence (\%) } & \multirow{2}{*}{\multicolumn{2}{|c|}{$[-/+95 \% \mathrm{Cls}]$}} & \multicolumn{3}{|c|}{ Trypanosome spp (\%) } \\
\hline & & & & & & T. brucei & T. congolense & T. vivax \\
\hline Makuyuni & 34 & 2 & 5.88 & 0.72 & 19.67 & 0 & 0 & 100 \\
\hline Mswakijuu & 85 & 6 & 7.05 & 2.63 & 14.73 & 0 & 33.3 & 66.67 \\
\hline Naitolia & 90 & 3 & 3.33 & 0.69 & 9.40 & 0 & 33.3 & 66.67 \\
\hline Ortukai & 30 & 1 & 3.33 & 0.08 & 17.22 & 0 & 100.00 & 0 \\
\hline
\end{tabular}

Table-2. Analysis of the association of various factors with prevalence of trypanosome infection in cattle

\begin{tabular}{|c|c|c|c|c|c|c|c|}
\hline \multirow{2}{*}{$\begin{array}{l}\text { Variable } \\
\text { Village }\end{array}$} & \multirow[t]{2}{*}{ No. examined } & \multirow[t]{2}{*}{ No. Posistive } & \multirow[t]{2}{*}{ Prevalence (\%) } & \multicolumn{2}{|c|}{$[-/+95 \% \mathrm{Cls}]$} & \multirow[t]{2}{*}{$\chi^{2}$} & \multirow[t]{2}{*}{ P- Value } \\
\hline & & & & & & & \\
\hline Makuyuni & 34 & 2 & 5.88 & 0.72 & 19.67 & & \\
\hline Mswakijuu & 85 & 6 & 7.05 & 2.63 & 14.73 & & \\
\hline Naitolia & 90 & 3 & 3.33 & 0.69 & 9.40 & & \\
\hline Ortukai & 30 & 1 & 3.33 & 0.08 & 17.22 & 4.72 & 0.030 \\
\hline \multicolumn{8}{|c|}{ Age of animals (years) } \\
\hline 1.5 to 2.5 & 72 & 4 & 5.55 & 1.53 & 13.62 & & \\
\hline$>2.5$ to 4.5 & 77 & 3 & 3.89 & 0.81 & 10.96 & & \\
\hline$>4.5$ & 70 & 5 & 7.1 & 2.35 & 15.88 & 5.21 & 0.810 \\
\hline \multicolumn{8}{|l|}{ Sex } \\
\hline Female & 144 & 4 & 2.47 & 0.76 & 6.95 & 1.04 & 0.032 \\
\hline \multicolumn{8}{|l|}{ BCS } \\
\hline Good & 184 & 5 & 2.7 & 0.88 & 6.22 & & \\
\hline Poor & 51 & 7 & 13.7 & 5.72 & 26.21 & 6.74 & 0.001 \\
\hline
\end{tabular}

Cis $=$ confidence intervals, $\chi^{2}=$ chi-square test, $\mathrm{P}=$ level of significance, $\mathrm{BCS}=$ body condition score

Statistical analysis: Data collected from each study animal and laboratory analyses were coded into appropriate variables and entered in Epi-info (version 6.04d, CDC, Atlanta, USA). Biostatistical analysis was performed using Epi-info (version 6.04, CDC, Atlanta, USA). The point prevalence (\%) was calculated for all data as the number of infected individuals divided by the number of individuals sampled x 100. Categorical data were analyzed by using Chi-square $\left(\div^{2}\right)$ test of independence. In all the analyses, a value of $p<0.05$ was considered significant.

\section{Results}

Results of Giemsa stained blood smear examination in cattle are given in Table-1. Out of the total 239 cattle examined, trypanosomes were detected in $12(5 \%$; 95\% Confidence interval $[\mathrm{CI}]=$ 2.6-8.6) animals. Trypanosome infection was found in all surveyed villages. Overall, $T$. vivax was the predominant species identified $(8 / 12 ; 66.6 \%)$ followed by $T$. congolense $(4 / 12 ; 33.3 \%)$. T. brucei was not detected in this survey. Significant factors influencing prevalence of trypanosome infection are given in Table-2. A significantly higher prevalence of trypanosomes infection was recorded in males compared to females.
The prevalence of trypanosomosis varied among sampling villages. Highly significant difference was observed between Mswaki juu and Ortukai, whereas no significant difference was observed between Mswaki juu and Makuyuni. With respect to body condition score, prevalence was significantly higher in animals with poor score than good score $(13.7 \% \mathrm{vs}$. $2.7 \%$ ). The difference in trypanosomes infections among the different age categories was not significant. However, the highest proportion of positives animals was observed at age group $>4.5$ years old.

\section{Discussion}

Microscopic examination of blood smears was used in the present study because of its simplicity and easy handling, even in a developing country, in addition to lacks of the equipments needed for ELISA and PCR in its rural districts. Magona et al., [14] reported $78 \%$ sensitivity and $27 \%$ specificity when compared to gold standard tests, i.e. ELISA and PCR.

The results of the study revealed that $T$. vivax is the most prevalent trypanosomes specie in the study population that constituted $66 \%$, followed by $T$. congolense $(33 \%)$.

The overall prevalence of trypanosomes infections recorded in the present study (5\%) was 
much lower than the corresponding values reported, for indigenous TSHZ of similar age range in Morogoro [5,15] and in Mtwara region, southern Tanzania [16] but slightly higher to the $1.3 \%$ recorded in mixed crossbred and indigenous TSHZ in the same region, Morogroro [17]. However, the low prevalence rate could be perhaps due to the limited number (10) of microscopic fields examined and the use of less sensitive diagnostic tool (thin blood smear) in this study.

The relevant data from western Africa, East and central Africa, and from other environments similar to those found in Tanzania, also indicate bovine trypanosomosis is prevalent and wide spread among cattle populations. For examples in other buffy coat and thin blood smear-based investigations, prevalences of $8.4 \%, 1.6 \%, 14.6 \%, 20.4 \%, 13.5 \%$ and $36 \%$ have been reported in Nigeria, Chad, Cameroon, Ethiopia, Zambia and Mozambique respectively [16,18,19,20, 21,22]. The apparent geographical variation in prevalences may reflect differences in the levels of cattle management system, regular use of trypanosome chemoprophylaxis, breeds, resistance to parasite and distribution and challenges by fly vectors $[23,24,25]$.

Two trypanosomes species, $T$.congolense and T.vivax were identified in this study, with the latter consistently being more common than $T$. congolense. This is the first report of trypanosomes infections in cattle in the study area. It was also evident that the prevalence of trypanosomes was higher in Mswaki juu, a village which share border with Tarangire National Park, than other surveyed villages. The differences observed in trypanosomes infections between the four villages, which are approximately 15-20 km apart, may be attributed to differences in the tsetse challenges or cattle management practices. Potential haematophagous insect vector other than tsetse flies, including mechanical insect vectors such as Stomoxy spp., Tabanus spp. and Haematopota spp., are also abundant in this livestock-wildlife interface zone, and the presence of game animals such antelopes and other ungulates are generally accepted to be the reservoir hosts of T.vivax from which the infections are transmitted to domestic ruminants [26].

In the present study, there was no significant difference between the prevalence of trypanosomes infections recorded between animal age groups, supporting the observations made elsewhere [17,27]. Although the prevalence among animal category of $>4.5$ years were observed to be higher when compared to age group 1.5 to 4.5 years, one hypothesis that can be advanced is perhaps this trend simply reflects the number of 'exposure years' as young stock age [23] Some studies have shown young Boran calves generally appearing to be more resistant to trypanosomosis than older animals [23]. Similar patterns, though based on serology, have been observed in earlier studies in Burkina Faso [28] and Ghana [29] involving trypanotolerant cattle.

The differences in trypanosomosis prevalence across ages are probably influenced by livestock management systems used in such areas [30]. However, further research is required to elucidate the role of management systems and the interaction between age and the different livestock management systems on the trypanosomes infection in different cattle ages and breeds.

Consistent to other studies on bovine trypanosomosis, males were found to be more prone to trypanosomes infection and susceptible to trypanosomosis than females [31]. In agreement to this study, a similar report in Ethiopia [32] indicated that the exposure rate and the proportion of trypanosomes parasite positive were higher among males than females. This may reflect the lowered immunity developed in animals following exposure to parasite [33,34]. Some studies have shown that animals infected with T.vivax develop immunity more readily than $T$. congolense infected [35]. Also there is evidence that $T$. vivax is less virulent and consequently cattle develop tolerance to T. vivax more easily than $T$. congolense. The present study revealed a lower prevalence of $T$. congolense from the study villages, which might be due to the lowered development of immunity in the cattle following exposure to this parasite [27]. In agreement with this hypothesis, animals with poor body score were at a higher risk of trypanosomosis than their in good health looking counterparts.

In this study, no attempt was made to undertake detailed investigations such as packed cell volume (PCV) profiles and entomological surveys, to determine the level of anemia, challenges and species of fly vectors present in the study area. Furthermore, detailed investigation of other potential risk factors i.e. cattle/ wild animal density and contact, vector and parasite control regime and their association with trypanosomes infections were not undertaken. Resources constraints affecting logistics and laboratory capacity were the main reason. However, information from previous entomological survey in the areas close to the surveyed villages has shown substantial flies and other biting flies such as Tabanus and Stomoxys spp. A further study to disclose the 
significance of the disease (mortalities, reduced production and reproduction and control cost), wild animal and cattle interaction and the vector challenges is therefore desirable.

\section{Conclusion}

Bovine trypanosomosis has been shown to be prevalent in Makuyuni division. In agreement with established evidences, this study also indicated administrative localities, sex, and body condition score as important risk factors for the distribution of bovine trypanosomosis in the area. Therefore further studies should be conducted to substantiate the above findings so that the actual prevalence of the disease and species involved is determined and a feasible method of prevention of infection with trypanosome parasites implemented. Given the threat posed to the communities and tourists by human African trypanosomosis [7], there may be a particularly severe (but largely unrecognized) public health risk in this livestock/ wild life eco-zone, where there are high densities of appropriate hosts (livestock, wildlife) and the considerable number of tourists that visit each year. Planned integrated disease control approaches against flies vector and the parasite host, which is likely to include public education about transmission cycle and threats, vector control through the use of impregnated fly traps, chemoprophylaxis, need to be improved and enforced.

\section{Author's contributions}

Emanuel S. Swai conceived and designed the study. Jackson E. Kaaya conducted field surveys and analyze samples. Emanuel S. Swai analyzed the data. Emanuel S. Swai and Jackson E. Kaaya drafted and revised the manuscript. All authors read and approved final manuscript.

\section{Acknowledgements}

The authors highly acknowledge participating livestock keepers for their cooperation and help. Field and laboratory work rendered by Mr. Khalid and VIC colleagues in the course of undertaking this survey is highly acknowledged. This survey was financially supported by PACE project.

\section{Competing interests}

Authors declare that they have no Competing interests.

\section{References}

1. Kristjanson, P. M.; Swallow, B. M.; Rowlands, G. J.; Kruska, R. L., Leeuw, P. N.(1999). Measuring the costs of African animal trypanosomosis: the potential benefits of control and returns to research. Agricultural systems, 59: 79-98.

2. Ministry of Agriculture and Cooperatives (1998). $13^{\text {th }}$ Coordination meeting on Farming in Tsetse Control Areas of East Africa, Kampala, Uganda, 7-8 May 1998. Prepared by Tsetse and Trypanosomiasis Control Section, Dar-es-Salaam, Tanzania.

3. Ford, J., Katondo, K. M. (1977). Maps of tsetse fly (Glossina) distribution in Africa 1973, according to sub-generic groups on scale of 1:5,000,000. Bull Anim Hlth Prod Afri, 15: 188-194.

4. Connor, R. J., Halliwell, R. W. (1987). Bovine trypanosomiasis in southern Tanzania: parasitological and serological survey of prevalence. Trop Anim Health Prod 19(3):165-72.

5. Malele, I. I.; Kapange, L. A.; Mashenga, G. A.; Ringi, D.; Macha, A., Msangi, A.(2007). Assesment of vector and animal African trypanosomosis(AAT) at Twatwatwa in Kilosa, Tanzania.Tanz Vet J, 24(2): 122-128.

6. Kibona, S. N.; Picozzi, K.; Matemba, L., Lubega, G. W. (2007). Characterisation of the Trypanosoma brucei rhodesiense isolates from Tanzania using serum resistance associated gene as molecular marker.Tanzan Health Res Bull, 9(1):25-31.

7. Kinung'hi, S. M.; Malele, I. I.; Kibona, S. N.; Matemba, L. E.; Sahani, J. K.; Kishamawe, C., Mlengeya, T. D.(2006). Knowledge, attitudes and practices on tsetse and sleeping sickness among communities living in and around Serengeti National Park, Tanzania.Tanzan Health Res Bull, 8(3):168172.

8. Sindato, C.; Malele, I. I.; Mwalimu, C.; Nyingilili, H. S.; Kaboya, S.; Kombe, E.; Msumary, C., Manoza, A.(2007). Seasonal variation in human African trypanosomiasis in Tarangire National Park in Babati district, Tanzania. Tanzan Health Res Bull 9(2):136139.

9. Mehlitz, D. (1987). Animal reservoir hosts for sleeping sickness: over view. In: Proceeding of the $19^{\text {th }}$ Meeting of the International Scientific Conference for Trypanosomosis Research and Control (ISCTRC), Lome, Togo, (OAU/STRC Publication No: 114), pp 213-219.

10. Anon. (2006). Monduli annual district report, pp 6-15.

11. Thrusfield, M. V. (2005). Veterinary Epidemiology, $3^{\text {rd }}$ Ed, Blackwell Science, Oxford, London, pp 234238.

12. Murray, M. D.; Clifford, J., McIntyre, W. I. M.(1979). Diagnosis of African Trypanosomiasis in bovine. Trans R Soc Trop Med Hyg, 73, 120-121.

13. Murray, M. D.; Murray, P. K., McIntyre, W. I. M. (1977). An improved technique for the diagnosis pf African trypanosomes. Trans $\mathrm{R}$ Soc Trop Med Hyg, 71:325-326.

14. Magona, J. W.; Mayende, J. S.; Olaho-Mukani, W.; Coleman, P. G.; Jonsson, N. N.; Welburn, S. C., Eisler, M.C.(2003). A comparative study on the 
clinical, parasitological and molecular diagnosis of bovine trypanosomosis in Uganda. Onderstepoort $J$ Vet Res, 70(3): 213-218.

15. Mugittu, K. N.; Silayo, R. S.; Majiwa, P. A.; Kimbita, E. K.; Mutayoba, B. M., Maselle. R. (2001). Application of PCR and DNA probes in the characterisation of trypanosomes in the blood of cattle in farms in Morogoro, Tanzania. Vet Parasitol, 94(3):177-189.

16. Nonga, H. E., Kambarage, D. M.(2009). Prevalence of bovine trypanososmis in Morogoro, Tanzania. Pakistan JNutr, 8(3): 208-213.

17. Delafosse, A.; Thébaud, E.; Desquesnes, M., Michaux, Y. (2006). Epidemiology of Trypanosoma vivax infection in cattle in the tsetse free area of Lake Chad. Prev Vet Med 74(2-3): 108-119.

18. Enwezor, F. N.; Umoh, J. U.; Esievo, K. A.; Halid, I.; Zaria, L. T., Anere, J. I. (2009). Survey of bovine trypanosomosis in the Kachia Grazing Reserve, Kaduna State, Nigeria. Vet Parasitol, 159(2):121-125.

19. Mbahin, N.; Zoli, A.; Mamoudou, A.; Tanenbe, C.; Abah, S.; Ghogomu, R.T.; Nouala, S. F., Njeumi, F. (2008). Parasitological prevalence of bovine trypanosomosis in Faro and Deo division Cameroon, ten years after the tsetse eradication campaign. Bull Anim Hlth Prod Afri, 56: 289-297.

20. Miruk, A.; Hagos, A.; Yacob, H. T.; Asnake, F., Basu, A. K. (2008). Prevalence of bovine trypanosomosis and trypanocidal drug sensitivity studies on Trypanosoma congolense in Wolyta and Dawero zones of southern Ethiopia. Vet Parasitol, 152(12):141-147.

21. Simukoko, H.; Marcotty, T., Phiri, I.; Geysen, D.; Vercruysse, J., Van den Bossche, P. (2007). The comparative role of cattle, goats and pigs in the epidemiology of livestock trypanosomiasis on the plateau of eastern Zambia. Vet Parasitol 147(34):231-238

22. Specht, E. J. (2008). Prevalence of bovine trypanosomosis in Central Mozambique from 2002 to 2005.Onderstepoort JVet Res, 75(1):73-81.

23. Dolan, R. B. (1998). The Orma Boran, A Trypanotolerant East African breed. KETRI, Kikuyu, Kenya. Pp 32-38.

24. Gachohi, J. M.; Bett, B., Murilla, G. A. (2009). Factors influencing prevalence of trypanosomosis in Orma Boran (trypanotolerant) and Teso zebu (trypanosusceptible) cattle crosses in Teso District, western Kenya, Livestock Research for Rural Development. Volume 21, Article \#216. Retrieved October 15, 2010, from http://www.lrrd.org/lrrd $21 /$ 12/gach21216.htm.
25. Murray, M.; Morrison, W. I., Whitelaw, D. D (1982). Host susceptibility to African trypanosomiasis: trypanotolerance. Adv Parasitol, 21: 1-68.

26. Van den Bossche, P.; Mudenge, D.; Mubanga, J. Norval, A.(1999). The parasitological and serological prevalence of tsetse-transmitted bovine trypanosomosis in the Eastern Caprivi (Caprivi District, Namibia). Onderstepoort J Vet Res, 66(2):103-110.

27. Yeshitila, A. Y.; Getachew, A.; Hagos, A., Basu, A. K.(2006). Prevalence of bovine trypanosomosis in Sokoru district, Jimma zone, Oromiya Region, South west of Ethiopia. Bull Anim Hlth Prod Afri 54: 242-258.

28. Desquesnes, M.; Bengaly, Z.; Millogo, L.; Meme, Y., Sakande, H. (2001). The analysis of the crossreactions occurring in antibody-ELISA for the detection of trypanosomes can improve identification of the parasite species involved. Ann Trop Med Parasitol 95(2):141-155.

29. Mahama, C. I.; Desquesnes, M. L.; Dia, M. L.; Losson, B.; De Deken, R., Geerts, S.(2004). A crosssectional epidemiological survey of bovine trypanosomosis and its vectors in the Savelugu and West Mamprusi districts of northern Ghana. Vet Parasitol, 122: 1-13.

30. Bett, B.; Orenge, C.; Irungu, P., Munga, L. K. (2004). Epidemiological factors that influence time-to-treatment of trypanosomosis in Orma Boran cattle raised at Galana Ranch, Kenya. Vet Parasitol, 120: 43-53.

31. Rowlands, G. J.; Leak, S. G.; Peregrine, A. S.; Nagda, S. M.; Mulatu, W., d'Ieteren, G. D. (2001). The incidence of new and the prevalence and persistence of recurrent trypanosome infections in cattle in southwest Ethiopia exposed to a high challenge with drug-resistant parasites. Acta Trop, 79(2):149-163.

32. Rowlands, G. J.; Mulatu, W.; Authié, E.; d'Ieteren, G. D.; Leak, S. G.; Nagda, S. M., Peregrine, A. S. (1993). Epidemiology of bovine trypanosomiasis in the Ghibe valley, southwest Ethiopia. 2. Factors associated with variations in trypanosome prevalence, incidence of new infections and prevalence of recurrent infections. Acta Trop, 53(2):135-150.

33. Godwin, L. G. (1970). The pathology of African Trypanosomosis. Trans $R$ Soc Trop Med Hyg, 64: 797-812.

34. Mansfiled, J.M.(1978). Immunobiology of African Trypanosomosis. Cell Immunol, 39: 204-210.

35. D'Iteren, G. D. M.; Authie, E.; Wisoeq, N., Murray, M. (1998). OIE Scientific and technical Review, pp 154. 